\title{
Factors associated with successful vaginal birth after cesarean section and outcomes in rural area of Anatolia
}

This article was published in the following Dove Press journal:

International Journal of Women's Health

10 July 2015

Number of times this article has been viewed

\author{
Mehmet Baki Senturk' \\ Yusuf Cakmak ${ }^{2}$ \\ Halit Atac ${ }^{2}$ \\ Mehmet Sukru Budak ${ }^{3}$ \\ 'Department of Obstetrics and \\ Gynecology, Bakirkoy Dr Sadi Konuk \\ Teaching and Research Hospital, \\ Istanbul, Turkey; ${ }^{2}$ Department of \\ Obstetrics and Gynecology, Batman \\ State Hospital, Batman, Turkey; \\ ${ }^{3}$ Department of Obstetrics and \\ Gynecology, Diyarbakir Research \\ Hospital, Diyarbakir, Turkey
}

\begin{abstract}
Successful vaginal birth after cesarean section is more comfortable than repeat emergency or elective cesarean section. Antenatal examinations are important in selection for trial of labor, while birth management can be difficult when the patients present at emergency condition. But there is an increased chance of vaginal birth with advanced cervical dilation. This study attempts to evaluate factors associated with success of vaginal birth after cesarean section and to compare the maternal and perinatal outcomes between vaginal birth after cesarean section and intrapartum cesarean section in patients who were admitted to hospital during the active or second stage of labor. A retrospective evaluation was made from the results of 127 patients. Cesarean section was performed in 57 patients; 70 attempted trial of labor. The factors associated with success of vaginal birth after cesarean section were investigated. Maternal and neonatal outcomes were compared between the groups. Vaginal birth after cesarean section was successful in 55\% of cases. Advanced cervical opening, effacement, gravidity, parity, and prior vaginal delivery were factors associated with successful vaginal birth. The vaginal birth group had more complications $(P<0.01)$, but these were minor. The rate of blood transfusion and prevalence of changes in hemoglobin level were similar in both groups $(P>0.05)$. In this study, cervical opening, effacement, gravidity, parity, and prior vaginal delivery were important factors for successful vaginal birth after cesarean section. The patients' requests influenced outcome. Trial of labor should take into consideration the patient's preference, together with the proper setting.
\end{abstract}

Keywords: cesarean section, trial of labor, vaginal birth after cesarean

\section{Introduction}

Women eligible for vaginal birth after cesarean (VBAC) section have lower morbidity rates than women who undergo subsequent elective cesarean sections (CSs). However, women undergoing intrapartum CS have relatively higher morbidity rates. ${ }^{1}$ The American College of Obstetricians and Gynecologists (ACOG) provides guidelines for birth interventions and for treating complications that may arise during VBAC (eg, uterine rupture and maternal and fetal death); several studies have recommended various approaches to identify patients who may undergo VBAC. ${ }^{1-4}$

In Southeastern Anatolia, there is cultural resistance to CS, with most women insisting on vaginal birth to be able to bear more children, resulting in large families. Women with a history of CS mostly undergo initial labor at home and present to hospitals with advanced labor to ensure vaginal delivery, opt for vaginal delivery at home, or present at hospitals with complications. ${ }^{5}$ This study evaluated 127 patients with a history of CS and without indication of prior CS who were admitted in the active or
Correspondence: Mehmet Baki Senturk Department of Obstetrics and Gynecology, Bakirkoy Dr Sadi Konuk Teaching and Research Hospital, Tevfik Saglam Street, Number II, Zuhuratbaba, Bakirkoy 34I47, Istanbul, Turkey

Tel +90 54l 773 7l76

Email dr.baki77@gmail.com 
second stage of labor to the Batman Women's Health and Children's Hospital in Southeastern Turkey. The results of repeat intrapartum CS were compared with those of vaginal birth. The factors governing the safety and success of a trial of VBAC were investigated.

\section{Materials and methods}

A retrospective evaluation was made of 127 patients with a history of CS who were admitted to the Batman Women's Health and Children's Hospital between January 2010 and May 2014, requesting vaginal birth while in the active or second stage of labor. Although all women were eligible for CS due to previous CS, CS and vaginal birth groups were identified according to consent for CS or no consent for CS. Trial of vaginal birth was performed after receiving consent from the patients insisting on vaginal delivery. A CS was considered to be indicated when requested by the patient or when other indications such as uterine rupture, acute fetal distress, and obstructed labor were detected. The demographic characteristics and clinical parameters of the patients were recorded. Postpartum neonatal complications, Apgar scores, maternal complications, and transfusion ratios, were compared between the two groups. The factors associated with the success of VBAC were investigated. The study was approved by the ethics committee of Batman State Hospital, Batman, Turkey.

The statistical software programs NCSS (Number Cruncher Statistical System) 2007 and PASS (Power Analysis and Sample Size) 2008 (Kaysville, UT, USA) were used for statistical analysis. Age, gravidity, parity, gestational week, cervical dilation, effacement, infant birth weight, Apgar scores, and hospitalization duration were compared with the Mann-Whitney $U$-test and Student's $t$-test. Comparisons of transfusion, neonatal and maternal complications, and labor stage were performed with the Yates, continuity correction and Fisher's exact tests. Comparisons of hemoglobin values and the relationship between the success of VBAC and cervical dilation were determined with the Mann-Whitney $U$-test. The relationship between the success of VBAC and prior vaginal delivery was evaluated with the Mann-Whitney $U$-test, Student's $t$-test and Yates' continuity correction test. $P<0.01$ and $P<0.05$ were considered statistically significant.

\section{Results}

Of 127 patients, 57 underwent CS and 70 delivered vaginally. Indications for intrapartum CS are reported in Table 1. The success of VBAC was 55\%. Cervical dilation and effacement were important factors for the success of VBAC $(95 \%$
Table I Indication for intrapartum cesarean

\begin{tabular}{ll}
\hline Indication & CS (n=57) \\
\cline { 2 - 2 } & $\mathbf{n}(\%)$ \\
\hline Fetal distress & $9(15.8)$ \\
Patient's request & $13(22.8)$ \\
Obstructed labor & $21(36.8)$ \\
Malpresentation & $10(17.5)$ \\
Uterine rupture & $4(7.0)$ \\
\hline
\end{tabular}

Abbreviation: CS, cesarean section.

[confidence interval] CI: 1.62-2.59 for dilation, CI: 1.06-1.14 for effacement). Gravidity, parity, and previous vaginal birth were also associated factors in the success of VBAC $(95 \%$ CI: $1.080-1.596$ for gravidity CI: $1.178-1.869$ for parity, and CI: 1.677-10.464 for previous vaginal birth) (Table 2).

While age, gravidity, parity, previous vaginal birth, cervical dilation, and effacement were statistically higher in the vaginal birth group $(P<0.01)$, hospitalization durations were shorter $(P<0.01)$. The number of cases presenting in the second stage of labor were significantly higher in the vaginal birth group $(P<0.01)$. There were no differences in other parameters between the groups $(P>0.01)$ (Table 2$)$.

Transfusion was performed in $12.9 \%(n=9)$ of the vaginal birth cases, and in $8.8 \%(\mathrm{n}=5)$ of CS cases. This difference was not significant $(P>0.05)$. Complications were observed in $27.1 \%(n=19)$ of the vaginal birth cases, and $3.5 \%(n=2)$ of the CS cases. This difference was significant $(P<0.01)$. Further examination revealed four dehiscences, one atony, and 14 vaginal tears in the vaginal birth group; and two dehiscences in the CS group. Primary repair was carried out on all dehiscences. No significant differences were determined between the neonatal complication rates $(P>0.05)$. In the vaginal birth group, the mean predelivery hemoglobin level was $11.79 \pm 1.60 \mathrm{~g} / \mathrm{dL}$, while the mean postpartum hemoglobin level was $10.43 \pm 1.37 \mathrm{~g} / \mathrm{dL}$; in the CS group, the corresponding values were $11.90 \pm 1.39$ and $10.43 \pm 1.37 \mathrm{~g} / \mathrm{dL}$, respectively. No significant differences were determined between the hemoglobin measurements before and after delivery $(P>0.05)$ (Table 3$)$.

Intrauterine fetal death occurred in one patient in the vaginal birth group, and dehiscence of the scar line was determined during follow-up after vaginal delivery. No maternal death was observed in either group.

\section{Discussion}

In this retrospective study, the success of VBAC was $55 \%$. There were no significant differences in outcome between delivery via intrapartum CS and delivery via vaginal birth. 
Table 2 Multi-logistic regression analysis

\begin{tabular}{|c|c|c|c|c|c|}
\hline & $\begin{array}{l}\text { Vaginal delivery } \\
(n=70)\end{array}$ & $\begin{array}{l}\text { Cesarean } \\
\text { section }(n=57)\end{array}$ & $P$-value & OR & $\begin{array}{l}95 \% \text { confidence } \\
\text { interval }\end{array}$ \\
\hline \multicolumn{6}{|c|}{ Cervical opening (cm) } \\
\hline Min-max (median) & $4-10(9)$ & $4-10(5)$ & $0.00 I^{\mathrm{a}, *}$ & 2.056 & $1.62-259$ \\
\hline Mean \pm SD & $8.31 \pm 2.05$ & $5.40 \pm 1.47$ & & & \\
\hline \multicolumn{6}{|l|}{ Effacement (\%) } \\
\hline Min-max (median) & $50-100(100)$ & $50-100(60)$ & $0.00 \mathrm{I}^{\mathrm{a}, *}$ & 1.106 & $1.06-1.14$ \\
\hline Mean \pm SD & $87.14 \pm 17.54$ & $62.45 \pm 9.50$ & & & \\
\hline \multicolumn{6}{|l|}{ Age (years) } \\
\hline Min-max (median) & $20-46(30)$ & $19-48(31)$ & $0.445^{b}$ & $\mathrm{n} / \mathrm{a}$ & $\mathrm{n} / \mathrm{a}$ \\
\hline Mean \pm SD & $29.97 \pm 5.16$ & $30.74 \pm 6.10$ & & & \\
\hline \multicolumn{6}{|l|}{ Gravidity } \\
\hline Min-max (median) & $2-9(5)$ & $2-13(3)$ & $0.00 I^{\mathrm{a}, *}$ & 1.313 & $1.080-1.596$ \\
\hline Mean \pm SD & $4.83 \pm 1.86$ & $3.8 I \pm 2.14$ & & & \\
\hline \multicolumn{6}{|l|}{ Parity } \\
\hline Min-max (median) & $\mathrm{I}-8(3)$ & $\mathrm{I}-7(2)$ & $0.00 \mathrm{I}^{\mathrm{a}, *}$ & 1.484 & $1.178-1.869$ \\
\hline Mean \pm SD & $3.53 \pm 1.74$ & $2.44 \pm 1.59$ & & & \\
\hline \multicolumn{6}{|c|}{ Gestational age (weeks) } \\
\hline Min-max (median) & $27-43(40)$ & $34-40(40)$ & $0.595^{b}$ & $\mathrm{n} / \mathrm{a}$ & $\mathrm{n} / \mathrm{a}$ \\
\hline Mean \pm SD & $39.23 \pm 2.23$ & $39.04 \pm 1.77$ & & & \\
\hline \multicolumn{6}{|l|}{ Birth weight (g) } \\
\hline Min-max (median) & $1,400-4,700(3,300)$ & $1,750-4,300(3,300)$ & $0.489^{b}$ & $\mathrm{n} / \mathrm{a}$ & $\mathrm{n} / \mathrm{a}$ \\
\hline Mean \pm SD & $3,284.29 \pm 544.91$ & $3,2 \mid 4.74 \pm 580.78$ & & & \\
\hline \multicolumn{6}{|c|}{ Prior vaginal delivery } \\
\hline Yes & $62(88.6 \%)$ & 37 (64.9\%) & $0.003^{c, *}$ & 4.189 & $1.677-10.464$ \\
\hline No & 8 (11.4\%) & 20 (35.1\%) & & & \\
\hline
\end{tabular}

Notes: aMann-Whitney U-test; 'Student's $t$-test; 'Yates' continuity correction test. $* P<0.01$.

Abbreviations: min, minimum; max, maximum; n/a, not assessed; OR, odds ratio; SD, standard deviation.

Cervical opening and effacement were the most significant factors influencing the success of VBAC, while other factors were gravidity, parity, and prior vaginal delivery.

Several studies have investigated factors associated with successful VBAC. For example, factors associated with a higher success rate include management by a certified midwife, presentation after a membrane rupture or in the active phase of labor, and greater cervical dilatation. Success rates have been reported to be the lowest in patients with meconium-stained amniotic fluid or a prolonged labor ( $>4$ hours). In these studies, patients were selected according to certain criteria, before the onset of labor, or earlier in the antenatal period. ${ }^{1,5,6}$ Other studies have focused on determining patients suitable for VBAC during the antenatal period.

Table 3 Comparison of transfusion, neonatal and maternal complications, and change in hemoglobin level

\begin{tabular}{|c|c|c|c|}
\hline & Vaginal delivery $(n=70)$ & Cesarean section $(n=57)$ & $P$-value \\
\hline \multicolumn{4}{|l|}{ Transfusion } \\
\hline Absent, n (\%) & $61(87.1)$ & $52(91.2)$ & $0.655^{\mathrm{a}}$ \\
\hline Present, n (\%) & $9(12.9)$ & $5(8.8)$ & \\
\hline \multicolumn{4}{|l|}{ Maternal complications } \\
\hline Absent, $n(\%)$ & $51(72.9)$ & $55(96.5)$ & $0.00 I^{a, *}$ \\
\hline Present, n (\%) & $19(27.1)$ & $2(3.5)$ & \\
\hline \multicolumn{4}{|l|}{ Neonatal complications } \\
\hline Absent, n (\%) & $65(92.9)$ & $54(94.7)$ & $0.730^{\mathrm{b}}$ \\
\hline Present, n (\%) & $5(7.1)$ & $3(5.3)$ & \\
\hline Predelivery HGB, mean \pm SD & $1 \mathrm{I} .79 \pm 1.60$ & $11.90 \pm 1.39$ & $0.683^{c}$ \\
\hline Postpartum HGB, mean \pm SD & $10.21 \pm 1.63$ & $10.43 \pm 1.37$ & $0.414^{c}$ \\
\hline$P$-value ${ }^{d}$ & $0.001 *$ & $0.001 *$ & \\
\hline Predelivery-postpartum change, mean \pm SD (median) & $\mathrm{I} .58 \pm \mathrm{I} .46(\mathrm{I} .2)$ & $1.47 \pm 0.76(1.5)$ & $0.308^{e}$ \\
\hline
\end{tabular}

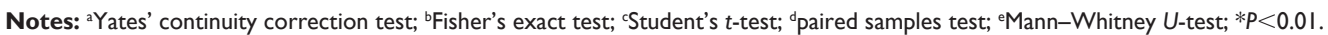

Abbreviations: $\mathrm{HGB}$, hemoglobin; SD, standard deviation. 
In a study investigating 515 patients, a model was developed based on six definitive criteria, which had a $72 \%$ successful VBAC rate. Those criteria included prepregnancy body mass index, previous vaginal delivery, previous nonprogression of labor, Caucasian race, induction during the present delivery, and an estimated fetal weight $P>90 .{ }^{3}$ Nevertheless, in cases where the patient presents in the active phase or second stage of labor and there is no data regarding the indication for the previous CS or antenatal history, the decision to proceed with a vaginal birth can be difficult for the physician, although the decision can be made more easily if delivery is imminent. Consistent with this, in the present study, the strongest factor predicting vaginal delivery was presentation during the advancing active or second stage, after experiencing labor pains at home. All studies of cervical factors have found that favorable cervical factors have been significantly associated with a successful trial of labor. Flamm and Geiger $^{7}$ demonstrated that women with dilatation greater than $4 \mathrm{~cm}$ on admission were significantly more likely to have VBAC compared with those with dilatation less than $4 \mathrm{~cm}$. Similarly, Macones et $\mathrm{al}^{8}$ and Pickhardt et $\mathrm{al}^{9}$ showed that the likelihood of VBAC increased significantly with each centimeter increase in cervical dilation. Flamm and Geiger ${ }^{7}$ also found that cervical effacement greater than $25 \%$ was associated with a significantly higher likelihood of vaginal delivery. Similar to Flamm and Geiger's ${ }^{7}$ findings, McNally and Turner ${ }^{10}$ found that those with effacement of $100 \%$ had a fivefold increase in the likelihood of VBAC compared with those with effacement less than $100 \%$. The current study demonstrated that cervical opening and effacement were associated with the success of VBAC (odds ratio [OR]: 2.056 and 1.106 , respectively).

Although there was no correlation between fetal factors and the success of VBAC in this study, gestational age and birth weight have been significantly associated with trial of labor outcome in literature. Two studies showed a negative association between gestational age and likelihood of VBAC. One case-control study found that for women with gestational age greater than 36 weeks, the likelihood of VBAC significantly decreased with each week. ${ }^{9}$ A retrospective cohort study of 2,775 women demonstrated that gestational age greater than 40 weeks was significantly associated with a decreased likelihood of VBAC compared with those with gestational age less than 40 weeks, for both spontaneous and induced labor. ${ }^{11}$ With regard to birth weight, two studies demonstrated that birth weight greater than 4,000 $\mathrm{g}$ was associated with a lower likelihood of vaginal delivery. ${ }^{12,13}$
Increasing parity was noted to be associated with an increase in VBAC rate. ${ }^{14}$ There is consistent evidence to show that a prior vaginal delivery is associated with a higher rate of successful VBAC compared with patients with no prior vaginal delivery. ${ }^{15-17}$ The current study has shown that women who had a prior vaginal delivery had a fourfold greater likelihood of VBAC (OR: 4.189). Also similar to other studies, gravidity and parity were found to be other important factors associated with the success of VBAC (OR: 1.313 and 1.484, respectively). Southeastern Anatolia is a low socioeconomic area compared to other regions of Turkey. In this area, most women insist on vaginal birth to be able to bear more children, resulting in large families. Women with low socioeconomic status are less likely to decline trial of labor after cesarean. ${ }^{18,19}$ Hence the numbers of gravidity and parity are high. Therefore, the physician must consider trial of labor in such women.

When comparing vaginal delivery with elective or intrapartum CS, VBAC appears to be safe. In a previous study of 151 patients, 96 delivered vaginally, while the rest underwent a CS. Among the indications for CS, malpresentation, the request of the patient, suspected cephalopelvic disproportion, and a lack of knowledge of prior surgery were the most common reasons. The vaginal delivery group and CS groups each had one case of dehiscence; there were no differences in neonatal outcomes. ${ }^{14}$ In another study of 190 patients eligible for vaginal delivery, 95 had vaginal delivery, and 1st minute Apgar scores of $<7$ were common in patients who underwent emergency CS. However, the indications for emergency CS, specifically for cases of acute fetal distress, were not stated. Cases of maternal and fetal death and rupture were also not indicated. ${ }^{20}$ While there were no intergroup differences in transfusion, neonatal outcomes, or changes in hemoglobin level in the current study, one case of intrauterine fetal death occurred in the vaginal delivery group, in a case of dehiscence, as determined during follow-up after vaginal delivery. While complication rates were higher in the vaginal delivery group, vaginal tears, which are a relatively minor complication, appear to increase this rate.

The limitations of this study include the retrospective design, the absence of data on the indications for previous $\mathrm{CS}$, and the limited number of cases. Moreover, several speculations arose owing to the absence of data of patients with prior CS who presented with complaints of rupture, fetal death, or massive hemorrhage after starting labor at home. There are six private hospitals in the province and it is thought that some of the missing patients might have presented at these hospitals. However, all the patients in this study had 
social security coverage and were of low socioeconomic status with healthcare cards for the uninsured. In Turkey, these patients may only utilize healthcare services offered by state hospitals. A thorough investigation of our hospital archives revealed that five patients underwent repeat CS after presenting at hospital between January 2010 and May 2014. There were no maternal or perinatal deaths in these cases. Peripartum hysterectomy was performed in two patients for placenta accreta, in two patients for rupture after vaginal delivery, and in one patient for atony.

Although it has some limitations, the present study demonstrates that the stage of labor affected the rate of VBAC. Patients' request seems to affect the stage of labor during admission to hospital. To the best of our knowledge, there are no reports of patients who present during the late active phase or second stage, and the interesting point of this study was that it involved patients who opted to present at the hospital upon reaching the late active phase or the second stage in order to ensure vaginal delivery by the physician upon the patient's insistence.

\section{Acknowledgments}

We specially thank the officers' archive of Batman State hospital for their assistance. This article's language has been edited by native English speaker Caroline Walker.

\section{Disclosure}

This study was not supported by any company or institution. The authors report no conflicts of interest in this work.

\section{References}

1. Metz TD, Stoddard GJ, Henry E, Jackson M, Holmgren C, Esplin S. How do good candidates for trial of labor after cesarean (TOLAC) who undergo elective repeat cesarean differ from those who choose TOLAC? Am J Obstet Gynecol. 2013;208:458.e1-e6.

2. American College of Obstetricians and Gynecologists. ACOG Practice bulletin no 115: vaginal birth after previous cesarean delivery. Obstet Gynecol. 2010;116:450-463.

3. Schoorel EN, van Kuijk SM, Melman S, et al. Vaginal birth after a caesarean section: the development of a Western European population-based prediction model for deliveries at term. BJOG. 2014;121:194-201.
4. Melamed N, Segev M, Hadar E, Peled Y, Wiznitzer A, Yogev Y. Outcome of trial of labor after cesarean section in women with past failed operative vaginal delivery. Am J Obstet Gynecol. 2013;209:49.e1-e7.

5. Akcay T, Gol K, Sahin I, Simsek M. The safety of vaginal birth after cesarean. T Klin J Gynecol Obst. 2001;11:224-227.

6. Birara M, Gebrehiwot Y. Factors associated with success of vaginal birth after one caesarean section (VBAC) at three teaching hospitals in Addis Ababa, Ethiopia: a case control study. BMC Pregnancy Childbirth. 2013;1:13-31.

7. Flamm BL, Geiger AM. Vaginal birth after cesarean delivery: an admission scoring system. Obstet Gynecol. 1997;90:907-910.

8. Macones GA, Hausman N, Edelstein R, Stamilio DM, Marder SJ. Predicting outcomes of trials of labor in women attempting vaginal birth after cesarean delivery: a comparison of multivariate methods with neural networks. Am J Obstet Gynecol. 2001;184:409-413.

9. Pickhardt MG, Martin JN, Meydrech EF, et al. Vaginal birth after cesarean delivery: are there useful and valid predictors of success or failure? Am J Obstet Gynecol. 1992;166:1811-1819.

10. McNally OM, Turner MJ. Induction of labour after 1 previous caesarean section. Aust N Z J Obstet Gynaecol. 1999;39:425-429.

11. Zelop CM, Shipp TD, Cohen A, Repke JT, Lieberman E. Trial of labor after 40 weeks' gestation in women with prior cesarean. Obstet Gynecol. 2001;97:391-393.

12. Weinstein D, Benshushan A, Tanos V, Zilberstein R, Rojansky N. Predictive score for vaginal birth after cesarean section. Am J Obstet Gynecol. 1996;174:192-198.

13. Zelop CM, Shipp TD, Repke JT, Cohen A, Lieberman E. Outcomes of trial of labor following previous cesarean delivery among women with fetuses weighing >4,000 g. Am J Obstet Gynecol. 2001;185:903-905.

14. Balachandran L, Vaswani PR, Mogotlane R. Pregnancy outcome in women with previous one cesarean section. J Clin Diagn Res. 2014;8: $99-102$.

15. Landon MB, Hauth JC, Leveno KJ, et al; National Institute of Child Health and Human Development Maternal-Fetal Medicine Units Network. Maternal and perinatal outcomes associated with a trial of labour after prior cesarean delivery. $N$ Engl J Med. 2004;351:25812589.

16. Hendler I, Bujold E. Effect of prior vaginal delivery or prior vaginal birth after cesarean delivery on obstetric outcomes in women undergoing trial of labour. Obstet Gynecol. 2004;104(2):273-277.

17. Caughey AB, Shipp TD, Repke JT, Zelop C, Cohen A, Lieherman E. Trial of labour after cesarean delivery: the effect of previous vaginal delivery. Am J Obstet Gynecol. 1998;179(4):938-941.

18. Pang MW, Law LW, Leung TY, Lai PY, La TK. Sociodemographic factors and pregnancy events associated with women who declined vaginal birth after cesarean section. Eur J Obstet Gynecol Reprod Biol. 2009;143:24-28.

19. Dunsmoor-Su R, Sammel M, Stevens E, Peipert JL, Macones G. Impact of sociodemographic and hospital factors on attempts at vaginal birth after cesarean delivery. Obstet Gynecol. 2003;102:1358-1365.

20. Ugwu GO, Iyoke CA, Onah HE, Egwuatu VE, Ezugwu FO. Maternal and perinatal outcomes of delivery after a previous Cesarean section in Enugu, Southeast Nigeria: a prospective observational study. Int $J$ Womens Health. 2014;13;6:301-305.
International Journal of Women's Health

\section{Publish your work in this journal}

The International Journal of Women's Health is an international, peerreviewed open-access journal publishing original research, reports, editorials, reviews and commentaries on all aspects of women's healthcare including gynecology, obstetrics, and breast cancer. The manuscript management system is completely online and includes

\section{Dovepress}

a very quick and fair peer-review system, which is all easy to use. Visit http://www.dovepress.com/testimonials.php to read real quotes from published authors. 